\title{
Neocristandade ou "A César o que é de César e a Deus o que é de Deus"? 0 Papel Público da Religião na Opinião de Jovens Católicos na Jornada Mundial da Juventude do Rio 2013
}

Marcelo Ayres Camurça*

\section{Resumo}

Este artigo busca através dos dados contidos no Relatório da Pesquisa na Jornada Mundial da Juventude 2013, no Rio de Janeiro, estabelecer uma comparação entre os perfis dos jovens católicos da América Latina e "Europa Católica", no que diz respeito à questão do papel público das religiões e do seu lugar no arranjo laico do Estado e das sociedades modernas.

\section{Palavras-chave}

Juventude. Catolicismo. Espaço Público.

\section{Abstract}

This article seeks to establish through the data contained in the World Youth Journey Research Report, 2013 in Rio de Janeiro, a comparison between the profiles of young Catholics in Latin America and in the "Catholic Europe", regarding the question of the public role of religions and their place in the secular arrangement of the state and modern societies.

\section{Keywords}

Youth. Catholicism. Public Space.

\footnotetext{
* Marcelo Ayres é professor titular e colaborador no Programa de Pós-graduação em Ciência da Religião da Universidade Federal de Juiz de Fora (UFJF); professor visitante na Universidade Estadual do Ceará (UECE) em 2018; e Bolsista de Produtividade 02 do CNPq. E-mail: mcamurca@terra.com.br.
} 


\section{Introdução}

A perspectiva de pensar a questão da relação das religiões com o Estado, a política e o domínio público de uma forma plural e diversificada no mundo adveio da crítica à concepção uniforme e eurocêntrica da noção de secularização empreendida por José Casanova (1994) e Talal Asad (2003). A partir dela abriu-se a alternativa para enfoques mais ampliados dessas realidades, que passaram a levar em conta contextos nacionais e civilizatórios, ritmos próprios, trajetórias particulares pelas quais a relação entre religião, modernidade e esfera pública vem se constituindo. Vários autores, a partir daí, passaram então ao esforço comparativo, a começar pelo próprio Casanova, com o cotejo entre os casos da Espanha, Polônia, Brasil e Estados Unidos (1994). Philippe Portier e Jacqueline Lagrée (2010) organizaram um compêndio, no qual diversos autores se debruçaram sobre as vias nacionais de construção do pacto da laicidade nos Estados Unidos, na França, no Canadá, em Israel, na América Latina, na China e na Índia. O próprio Portier (2011) já havia se dedicado à abordagem comparativa entre os "regimes de regulação do crer" nos países da Europa e Jean-Paul Willaime (2011) também empreendeu uma comparação entre regimes de laicidade nos países da Europa. No Brasil, a se destacar o esforço teórico de Emerson Giumbelli, quando, ao discutir os termos "secularismo" e "laicidade", procura o entendimento dessas concepções na França, Uruguai, México e Brasil (GIUMBELLI, 2013, p. 43-68).

Nesse sentido, minha contribuição a esta grande pesquisa realizada com os participantes da Jornada Mundial da Juventude (doravante citada pela sigla JMJ) no Rio de Janeiro, em 2013, sob a coordenação dos cientistas sociais Cecília Mariz e Paulo Gracino, foi de aproveitar a presença de indivíduos provenientes de distintos lugares (a despeito de todos eles professarem a mesma religião católica), para medir a sua percepção acerca das diferentes modalidades de encaixe da religião no espaço público.

Do vasto questionário da pesquisa com 218 perguntas/assertivas e as estatísticas das respostas, selecionei aquelas que julgo dizer respeito e revelar as opiniões desses jovens católicos dos diferentes continentes do globo sobre a questão do papel público das religiões e o seu lugar no arranjo laico do Estado e das sociedades modernas.

A estrutura de coleta dos dados dessa pesquisa quantitativa baseou-se inicialmente em perguntas para serem respondidas no estilo "sim" e "não", assim como designar grupos e posições a que o respondente pertence e/ou 
assume. Em seguida, a maioria das questões parte de um enunciado sobre o qual o indivíduo declara se concorda (com variações), se é indiferente ou se discorda (com variações).

O resultado da pesquisa oferece inicialmente estatísticas para os seguintes grupos: total dos participantes da Jornada; total dos participantes do Brasil e total dos participantes do estrangeiro. Como desdobramento, os autores desse survey decidiram classificar a procedência desses jovens católicos em cinco grandes grupos: América do Sul, América do Norte, Europa (+católica), Europa (outros) e Outros.

Decidi não fazer uma comparação entre o total dos brasileiros e o total dos participantes estrangeiros, pois isto significaria, por contraste, falar de fato mais do Brasil, com um risco de não sair de certo paroquialismo diante de números tão significativos vindos de outras partes do mundo. Além disso, em outro texto (Camurça, 2015), também construído em cima dos números dessa vultosa pesquisa, já tinha feito uma comparação dos católicos brasileiros com os da Europa, tomando como base comparativa um artigo baseado em survey aplicado pela socióloga Danièle HérvieuLéger (1996) para a JMJ de 1991 na Polônia. Nesse texto, segundo a autora, a postura dos jovens católicos europeus era mais "intimista" e subjetiva, e o que encontrei nas respostas dos brasileiros nas JMJ de 2013 indicava uma posição mais "programática" e alinhada com a hierarquia da Igreja.

O voltar-se para esses números muito amplos do survey das JMJ do Rio em 2013 estimula uma perspectiva comparativa de fôlego entre os cinco grupos continentais (América do Sul, América do Norte, Europa (+católica), Europa (outros) e Outros). Embora uma comparação entre todos esses grupos fornecesse um quadro mais complexo em termos das várias situações de relação entre religião e espaço público, decidi seccionar do conjunto apenas os dados para a América Latina e Europa (+católica), por razões de economia e por ter um pouco mais de familiaridade com os estudos sobre essas regiões.

Em termos de uma interpretação sobre o recorte dos tipos "América Latina" e "Europa mais católica", adotado pela pesquisa, teria a dizer o seguinte, baseado em uma literatura especializada: para o tipo "América Latina", Roberto Blancarte (2011, p.182-206) afirma que esta é constituída de países com hegemonia católica e, por isso, os regimes de laicidade que nela se estabeleceram foram produto de uma "lógica de confrontação" e enfrentamento entre os postulados do liberalismo político por sobre os dogmas e valores cristalizados da instituição católica. Depois do recuo 
religioso, uma situação de negociação e pacto entre Estado e Igreja perdurou. No atual momento, devido ao processo de democratização ocorrido nessas sociedades, o que resultou num maior reconhecimento da diversidade, dos direitos humanos, sexuais e reprodutivos, e ainda o despontar de um quadro de pluralidade religiosa, uma tensão entre dois projetos se coloca. Um que o autor chama de "laicidade", voltado para a gestão democrática da diversidade, seus comportamentos e ethos, e outro que chama de "pluriconfessionalidade", em que o Estado passa a estender os privilégios outrora outorgados apenas à Igreja Católica a outras religiões com igual capacidade de mobilização e organização (BLANCARTE, 2011, p. 203-205). Jean Baubérot (2015, p. 88-89) também estima uma mudança no continente, de um "nacionalismo católico", que sustentava os Estados, para uma situação de pluralismo, em que a influência católica compete com partidos e líderes evangélicos em meio a uma situação de "clientelismo religioso".

Para o tipo "Europa católica", Philippe Portier (2011, p.11-12) afirma que a Europa ocidental possui distintas articulações para regular a relação entre o político e o religioso, forjadas em termos de disposições jurídicas. No caso dos países de maioria católica, criou-se um "sistema separatista" erigido sobre o fundamento de uma "dissociação institucional" com a Igreja Católica dominante Essa relação é regida por dois princípios: o do "distanciamento do Estado" das religiões, funcionando como um árbitro neutro e regulador dessas, e o da autonomia das religiões, fixadas em condição de igualdade perante esse Estado. Em alguns países católicos europeus estabeleceuse uma "separação flexível" com cooperação, na forma de concordatas e acordos entre religiões e Estado (PORTIER, 2011, p.15-16), principalmente com a religião que se sobressai, a católica, digo eu. Já para o historiador português Fernando Catroga (2006), a "Europa mais católica" se encontra associada aos casos de Portugal, Espanha e Itália, países católicos do sul da Europa que viveriam uma situação de "quase laicidade", devido à influência marcante da Igreja Católica no ambiente público e estatal. Baubérot (2015, p.104), por sua vez, avalia que países como Itália e Espanha passaram de um regime confessional católico do Estado para outro separatista, em que se estabelecem acordos e concordatas entre o Estado e as religiões, porém com um peso diferenciado para o catolicismo em termos de presença social e moral na sociedade. Ari Oro (2011, p.223) também sustenta que, a despeito da separação Igreja-Estado, há uma "relação preferencial" com a Igreja Católica sustentada "em acordos bilaterais e concordatas". 
Gostaria, para concluir esta introdução, dizer que o relatório final da pesquisa, no que diz respeito a seus resultados, organizou-se por seções, que não necessariamente estou seguindo nesta minha apropriação de seus dados. Recolhi perguntas e enunciados, suas respostas, frequências e estatísticas de sessões diferentes e as reagrupei segundo meu interesse para a exposição deste texto. Mantive, contudo, para aqueles leitores que desejarem fazer a identificação das perguntas e enunciados no relatório original, o número de cada uma delas e deles.

\section{A. Valorações diferentes entre o meio religioso e o mundo público}

\section{A.1 - Participação na sociedade ou na comunidade religiosa}

1- Como se define politicamente? (pergunta 72)

América Latina: direita $=18,5 \%$, centro-direita $=3,8 \%$ (total $=22,3 \%$ ); centro $7,1 \%$; esquerda $9,2 \%$, centro-esquerda $5,9 \%$ (total $=15,1 \%$ ); não sei $=16,5 \%$ e nenhum $30,0 \%$

Europa: direita $=16,3 \%$, centro-direita $=15,6 \%$ (total do campo $=31,9 \%$; centro $13,3 \%$; esquerda $11,9 \%$ e centro-esquerda $=3,0 \%$ (total $=14,9 \%$ ); não sei $=20 \%$ e nenhum $13,3 \%$

Constata-se uma considerável presença da direita e centro-direita como opção política desses jovens católicos, tanto na América Latina quanto na Europa católica. Mas, além disso, são muito significativos os índices de não definição dentro do espectro político (somando-se os "não sei" e "nenhum", chega-se a um total de $46.5 \%$ para a América Latina e 33,3\% para e Europa), superando as definições de esquerda, centro e direita, e indicando nesse segmento um afastamento dos valores da política. Parece que essas declarações acompanham o descenso da esquerda e social democracia e conquista do poder pela direita em governos da América Latina (VELASCO; CRUZ; KAYSEL; CODAS, 2015) e Europa (MUIS; IMERZEEL, 2017); assim como o crescente absenteísmo da política partidária, também notado nesses países. 


\section{A.2 - Participação em grupos da Igreja Católica? (pergunta 48)}

América Latina 71,2\% (sim) e 27, 4\% (não). Europa 40\% (sim) e 59,9\% (não)

Interessante que na América Latina verifica-se uma participação muito consistente de grupos organizados dentro da Igreja Católica, ao passo que na Europa observa-se o contrário, uma maioria que não está perfilhada a esses agrupamentos dentro da Igreja. Esses dados apontam para a tendência já sublinhada nos estudos de Hervieu-Léger (2003, p. 292) sobre o estilo individualizado e subjetivo de prática religiosa na Europa, incluso no Catolicismo. Essa autora detecta uma mudança na forma de adesão à Igreja por parte dos católicos mais jovens, na direção do abandono das formas normativas de adesão em detrimento de um "sentido pessoal de pertença". Tal dinâmica deriva de uma autonomização relativa desse católico em relação à estrutura eclesial (HERVIEU-LÉGER, 2003, pp. 296-297).

No que diz respeito a uma interpretação desse expressivo número de adesões a grupos organizados dentro da Igreja Católica na América Latina, considero que para essa realidade estabelece-se uma relação orgânica entre movimentos juvenis organizados com a hierarquia e o clero numa integração que visa a um projeto comum, já chamado de "reconquista" da influência católica na sociedade modernizada. (CARRANZA, 2011).

Nesses grupos juvenis observa-se uma postura de marcar presença no meio moderno e laico no sentido de convertê-lo. Grupos carismáticos promovem um processo de porosidade de suas práticas religiosas com estilos e ethos da vida laica contemporânea, uma forma moderna envolvendo um conteúdo conservador de oposição aos costumes mundanos, como sexo antes do casamento, uso de preservativos e práticas homoafetivas. Da mesma forma, grupos jovens tradicionalistas não carismáticos, como a Opus Dei, visam espraiar a mensagem do Cristo para o ambiente "anticristão" da sociedade secular (BRUM PEREIRA, 2014, pp. 07-08).

Por outro lado, irá aparecer uma grande frequência de declarações desses jovens católicos sugerindo um afastamento do meio secular. Para tal, vale a pena fazer uma associação com a pesquisa de Fernandes (1993, p.11-17) sobre a baixa participação civil dos evangélicos do Rio de Janeiro em associações e partidos políticos, ao passo que sua participação nas comunidades de culto atinge $84 \%$ de frequência (ou seja, a sociabilidade dentro da igreja aumenta na razão inversa daquela no meio laico e político (FERNANDES, 1993, p.14). 


\section{A.3 - Grupos dos quais participam (pergunta 49)}

América Latina: Grupos de jovens $=13,4 \%, \operatorname{RCC}=13,0 \%$, Pastoral $=10 \%$, Neocatecumenato $=4,1 \%$, Regnum Christi 1,6\%, Opus Dei $=1,4 \%$, Agostinianos $=0,6 \%$, Shalom $=1,4 \%$, Salesianos $=1,4 \%$, Outros $=50,3 \%$

Europa: Grupos de jovens $=5,6 \%, \operatorname{RCC}=5,6 \%$, Pastoral $=1,9 \%$, Neocatecumenato $=22,2 \%$, Regnum Christi 1,9\%, Opus Dei $=3,7 \%$, Agostinianos $=5,6 \%$, Outros $=39,3 \%$

Importante frisar, no que diz respeito ao aspecto organizativo, que sobressaem numa faixa de 50,3\% para a América Latina e 39,9\% para a Europa grupos não identificados e disseminados no tecido da Igreja Católica. Dos que são identificados, nota-se uma prevalência daqueles com perfil mais conservador (RCC, Neocatecumenato, Regnum Christi e Opus $D e i)$, superando com boa vantagem os ditos progressistas (Pastoral). Há, sem dúvida, uma correlação da pertença a esses grupos com as declarações anteriores acerca de um posicionamento no espectro político. Mas chama também atenção o percentual considerável de "grupos jovens" genéricos, que, somados ao número expressivo dos "outros", pode indicar uma ligação mais pessoal, familiar, cultural e ritual à Igreja, e não doutrinária como aquela dos grupos mais definidos. Isto poderá explicar a flutuação em termos de previsibilidade, nas opiniões dadas às questões da pesquisa.

Para me auxiliar no reconhecimento e tipificação dos grupos presentes à JMJ 2013, no caso da América Latina, recorro a uma tipologia estabelecida por Flavio Sofiati (2014, p.59-82). Esse autor, visando encontrar "elementos para a constituição de uma sociologia da juventude católica no Brasil" atual, baseou-se em outra tipologia realizada por Michael Löwy (2000) sobre as "tendências" dos agrupamentos mais representativos da Igreja Católica. Segundo essa tipologia, esses grupos estariam divididos em "modernizadores conservadores", representados na Renovação Carismática Católica (RCC), "tradicionalistas" (Opus Dei, TFP, Arautos do Evangelho), "radicais" da Teologia da Libertação (TL) e das Comunidades Eclesiais de Base (CEBs) junto com as Pastorais Sociais e, por fim, "reformistas" (salesianos e maristas) (SOFIATI, 2014, pp. 60-62).

Se aplicarmos essa tipologia aos grupos que apareceram nas declarações dos jovens católicos da América Latina presentes à Jornada (descontados os 50,3\% de grupos não identificados), temos em destaque os grupos carismáticos, classificados por Sofiati como "modernizadores 
conservadores" com 14,4\% (Renovação Carismática 13,\% + Shalom 1,4\%,) superando os "tradicionalistas" com 7,1\% (Neocatecumenato 4,1\% + Opus Dei 1,4\% + Regnum Christi 1,6\%,) Além disso, se somarmos os "modernizadores conservadores" com os "tradicionalistas", chegaremos a um total de $21,5 \%$, que indica um perfil conservador muito consolidado como corrente de opinião. Em seguida, aparecem os "Grupos de jovens" com expressivos 13,4\%, difíceis de precisar em termos de posição doutrinária, aproximando-se da visão dos jovens dispersos nas paróquias. E se somarmos estes aos 27,4\% que declararam não possuir pertencimento grupal, afora sua condição de fiel à Igreja Católica, poderemos entender a flexibilidade no conjunto das respostas da América Latina em posições de desencaixe a um alinhamento com a hierarquia eclesiástica. Temos ainda os índices de 10\% representando as Pastorais, classificados como "radicais" por Sofiati e, por fim, os "reformistas", Agostinianos 0,6\% e os Salesianos com $1,4 \%$ perfazendo um total de apenas $2 \%$. Esses três últimos, soma de "radicais" e "reformistas" (12\%), apontam para a existência de concepções ditas progressistas, mas numa condição minoritária.

Aplicando a mesma tipologia de Sofiati ao caso europeu, encontrase da mesma forma que na América Latina um percentual avultado de grupos não designados: 39,3\%, embora, quanto aos "Grupos de jovens" genéricos, estes sejam de apenas 5,6\%. Esses indicadores, da mesma forma que na América Latina, poderão sugerir nas respostas ao questionário da pesquisa as flutuações em relação a uma posição mais definida e alinhada à oficial da Igreja. Porém, numa proporção ainda maior do que na América Latina, aparece com destaque a realidade de grupos mais orgânicos e adesos à hierarquia, o que transparece nas declarações de pertença aos "tradicionalistas" com um percentual de $27 \%$, produto da soma dos jovens aderentes ao Neocatecumenato com 22,2\% mais os da Opus Dei com 3,5\%, os da Regnum Christi com 1,9\%. Os "modernizadores conservadores" carismáticos ficam com apenas 5,6\%, na mesma proporção dos "reformistas", salesianos com 5,6\%, restando uma ínfima declaração para as Pastorais: 1,9\%. Nessa porção católica da Europa, intuo que, por força do catolicismo tradicional na Itália, Polônia e países ibéricos, se nota uma presença organizada predominantemente conservadora de 32,6\% (soma de tradicionalistas $27 \%+5,6 \%$ dos carismáticos) diante de uma quase inexistência do chamado catolicismo social (que teve tanta pujança em países como a França e Alemanha) com 1,9\%, aqui ainda representado na faceta "reformista" dos salesianos com 5,6\%. 


\section{B. Confiança nas Instituiç̧ões Públicas}

\section{B.1 - Confiança no Governo (pergunta 88)}

América Latina: Totalmente $=2,9 \%$, confio $=25,2 \%($ total $=28,1 \%)$, indiferente $=10,2 \%$, não confio $=46,2 \%$, maneira nenhuma $=15,0 \%$ (total $=$ $61,2 \%) \mathrm{NR}=0,5$

Europa: Totalmente $=3,0 \%$, confio $=26,7 \%($ total $=29,7 \%)$, indiferente $=$ $25,2 \%$, não confio $=34,8 \%$, maneira nenhuma $=10,4 \%($ total $=45,2 \% \%)$

B2- Confiança nos Partidos Políticos (pergunta 94)

América Latina: Totalmente $=2,7 \%$, confio $=15,0 \%($ total $=17,7 \%)$, indiferente $=11,0 \%$, não confio $=52,0 \%$, maneira nenhuma $=18,3 \%$ $($ total $=70,3 \%) \mathrm{NR}=1,0 \%$

Europa: Totalmente $=2,2 \%$, confio $=16,3 \%($ total $=18,5 \%)$, indiferente $=$ $35,6 \%$, não confio $=31,1 \%$, maneira nenhuma $=14,1 \%($ total $=45,2 \%), N R=0,7$

B3 - Confiança na Igreja (pergunta 90)

América Latina: Totalmente $=72,2 \%$, confio $=24,6 \%$ (total $=96,8 \%)$, indiferente $=0,8 \%$, não confio $=1,1 \%$, maneira nenhuma $=0,7 \%$ (total $=$ $1,8 \%)$

Europa: Totalmente $=67,4 \%$, confio $=29,6 \%$ (total $=97 \%$, indiferente= $3,0 \%$, não confio $=0 \%$, maneira nenhuma $=0 \%($ total $=0 \%)$

Destaca-se nas respostas o alto nível de rejeição às instituições do Estado moderno e da chamada democracia representativa - "governo e "partidos políticos". Essa desconfiança atinge proporções muito altas na América Latina, $61,2 \%$ e 70,3\%, e na Europa também níveis bastante consistentes, $45,2 \%$ e $45,2 \%$. Em ambos os casos os percentuais parecem sugerir, na chamada crise da modernidade, o fenômeno que Dubet (2002) chamou de "declínio das instituições" modernas. Na proporção inversa, os indicadores de confiança para com a instituição Igreja Católica alcançam níveis quase totais de 96,8\% para a América Latina e 97\% para a Europa. Essa imensa credibilidade de uma instituição que abriga no seu seio, dentro de seu estilo milenar de circundata varietate (1986:28-31), uma grande gama de grupos de juventude de matizes diferentes e também de jovens avulsos ou participantes de suas paróquias locais era previsível. A variação, contudo, vai ocorrer 
na forma como esses grupos e indivíduos se posicionam dentro do grande guarda-chuva que os abriga a todos, de uma maior autonomia individual, passando por um alinhamento orgânico, até uma falta de reflexividade e naturalização de sua pertença. Em minha opinião, a constância ou variação das respostas dos jovens católicos na JMJ, vai oscilar de acordo com a condição e posição que ocupam dentro da instituição.

\section{Concepções de laicidade e do papel público da religião}

\section{C.1 - Religião e Política}

C.1.1 - Governos devem manter financeiramente as religiões (questão 203) América Latina: Concordo $=9,9 \%$; concordo parcialmente $=27,1 \%$ (total $=37 \%$, indiferente $=8,5 \%$, discordo parcialmente $=32,4 \%$, discordo totalmente $=20,8 \%($ total $=53,2 \%), \mathrm{NR}=1,1 \%$

Europa: Concordo $=9,6 \%$, concordo parcialmente $=29,6 \%$ (total $=39,2 \%$, indiferente $=20,7 \%$, discordo parcialmente $=30,4 \%$, discordo totalmente $=$ $9,6 \%$ (total $=40 \%)$

C.1.2 - Governos devem manter financeiramente a Igreja Católica (questão 205)

América Latina: Concordo $=12,0 \%$, concordo parcialmente $=25,7 \%$ (total $=37,7 \%$, indiferente $=7,6 \%$, discordo parcialmente $=32,6 \%$, discordo totalmente $=21,1 \%($ total $=53,7 \%) \mathrm{NR}=1,0 \%$

Europa: Concordo $=13,3 \%$, concordo parcialmente $=30,4 \%($ total $=43,7 \%)$, indiferente $=17,8 \%$, discordo parcialmente $=28,1 \%$, discordo totalmente $=$ $10,4 \%($ total $=38,5 \%)$

Interessante a posição expressa nas declarações de concordância e discordância, principalmente no que tange à América Latina, de rejeição ao financiamento governamental às religiões, 53,2\%, e particularmente à Igreja Católica, 53,7\%. Essas declarações inesperadamente discrepam da realidade da América Latina, onde historicamente a religião católica foi favorecida pelos governos como religião oficial, em seguida privilegiada em concordatas e acordos. Nesses países, afora momentos fugazes em que um liberalismo positivista imperante confiscou bens eclesiásticos, estabeleceu registro civil de nascimentos e casamentos e secularizou cemitérios, o 
estabelecimento de suas oligarquias no poder selou pactos com a Igreja Católica, em que esta aparecia como legitimadora da ordem moral do regime. Concordatas foram firmadas no Peru, em 1875, na Colômbia, em 1887, na Bolívia, em 1925. No Brasil, no governo Vargas, e na Argentina, na década de 1930, pactuaram-se "concordatas morais", em que o catolicismo como uma das "tradições nacionais" funcionava como base ideológica desses regimes (BLANCARTE, 2011, pp.201-202).

Mesmo na atualidade, ainda se firmam protocolos, como o que foi realizado entre o Vaticano e o Brasil na forma de Concordata em 2008, assegurando à Igreja garantias fiscais, proteção de lugares de culto e do patrimônio histórico cultural dos seus bens, além da destinação de espaços públicos para atos religiosos católicos, oferta de capelanias para sacerdotes católicos em hospitais e presídios, ensino religioso em escolas públicas e efeitos civis do casamento religioso (RANQUETAT JR., 2010, p. 176). No que tange à Argentina, o artigo $2^{\circ}$ de sua Constituição estabelece que o governo federal deva sustentar o culto católico (ESQUIVEL, 2010, p.153). E apesar das transformações operadas na Constituição de 1994 quanto à autonomia do governo em relação ao catolicismo, ainda seguem existindo dispositivos legais que asseguram à Igreja um "caráter público", ao passo que as demais religiões possuem um "caráter privado" (ESQUIVEL, 2010, p.156). Autoridades eclesiásticas recebem uma prebenda governamental, têm ajuda de custo para passagens e até passaportes diplomáticos (ESQUIVEL 2010, pp.155-56).

Para esse inopinado descompasso entre declarações autonomistas e situações de fato de concessões e privilégio, apresentam-se duas conjecturas: uma primeira de que o peso das respostas do expressivo segmento dos jovens católicos não pertencentes a grupos declaradamente conservadores tenha influído no resultado, e uma segunda, que considera que as respostas possam ser provenientes também dos grupos religiosamente conservadores declarados, pois entre suas concepções pode estar aquela de separar religião e "mundo", lugar do pecado e iniquidade. Desta forma, podem pensar que a Igreja não deve pactuar com essas esferas, sob pena de se contaminar com sua malignidade.

Ao contrário, também impressiona, para o caso da Europa, região promotora das transformações sociais na direção da modernidade e secularização, a flagrante resistência à autonomia do Estado em relação às religiões: no caso do financiamento estatal, as religiões em geral, 40\% discordam; no entanto, um quase igual número de 39\% concordam, e no 
caso de financiamento, a Igreja Católica, a maioria concorda: $43 \%$. Como interpretação do fenômeno, a explicação pode estar na marca católica dessa porção da Europa, dos países Itália, Espanha e Portugal, já classificados por Catroga (2006) como vivendo uma "quase laicidade". Na Itália e Espanha, países onde a Igreja Católica exercia sozinha o controle do ensino público, das subvenções estatais e o direito de elaboração de legislação civil, na atualidade essas concessões são estendidas às demais confissões religiosas (PORTIER, 2011, p.18). Também na Alemanha, o poder público financia instituições religiosas e as tem como parceiras em iniciativas de atividades sociais do seu Estado-providência (PORTIER, 2011, p.16-18).

C.1.3 - Políticos religiosos são mais honestos que os não religiosos (questão 146)

América Latina: Concordo $=9,9 \%$, concordo parcialmente $=25,3 \%$ (total $=35,2 \%$, indiferente $=10,3 \%$, discordo parcialmente $=32,4 \%$, discordo totalmente $=21,0 \%($ total $=53,4 \%), \mathrm{NR}=1,0 \%$

Europa: Concordo $=9,6 \%$, concordo parcialmente $=17,8 \%($ total $=27,4 \%)$, indiferente $=24,4 \%$, discordo parcialmente $=28,9 \%$, discordo totalmente $=$ $17,8 \%($ total $=53,3 \%), \mathrm{NR}=1,5 \%$

C.1.4 - Políticos católicos são mais honestos que os não católicos (questão 148)

América Latina: Concordo $=8,4 \%$, concordo parcialmente $=25,3 \%$ (total $=33,7 \%$, indiferente $=10,3 \%$, discordo parcialmente $=30,1 \%$, discordo totalmente $=17,5 \% \quad($ total $=47,6 \%), \mathrm{NR}=0,5 \%$

Europa: Concordo $=11,1 \%$, concordo parcialmente $=20,7 \%$ (total $=32,8 \%$ ), indiferente $=19,3 \%$, discordo parcialmente $=25,9 \%$, discordo totalmente $=$ $20,0 \%($ total $=45,9 \%), \mathrm{NR}=3,0 \%$

\section{C.1.5 - Votaria em candidato por sua orientação religiosa (questão 150)}

América Latina: Concordo $=15,1 \%$, concordo parcialmente $=25,3 \%$ (total $=40,4 \%$, indiferente $=8,3 \%$, discordo parcialmente $=25,0 \%$, discordo totalmente $=25,7 \%($ total $=50,7 \%), \mathrm{NR}=0,5 \%$

Europa: Concordo $=10,4 \%$, concordo parcialmente $=28,1 \%($ total $=38,5 \%$, indiferente $=21,5 \%$, discordo parcialmente $=22,2 \%$, discordo totalmente $=17,8 \%($ total $=28,1 \%), \mathrm{NR}=3,0 \%$ 
Interessante o resultado das respostas que relativizam o valor do componente religioso no campo da ética política. Tanto na América Latina quanto na Europa católica, os jovens católicos discordam que um político religioso seja mais honesto que um não religioso, e pasmem! que um político católico seja mais honesto que um não católico. O grau de discordância no primeiro caso é de 53,4\% para América Latina e de 53,3\% para a Europa, e no segundo, em que o fato de ser católico não distingue sua honestidade, de 47,6\% para a América Latina e 45,9\% para a Europa católica. Apenas no quesito que pergunta se o voto em um candidato religioso deva ser privilegiado, a América Latina mantém uma discordância de 50,7\% em relação a 40,4\% de concordância, mas, na Europa, o peso da religião induz ao voto desses jovens em $38,5 \%$ contra $28,1 \%$. Neste caso, pode-se especular que a presença mais consistente de grupos de juventude tradicionalistas/ conservadores nessa parte católica do velho continente, como apontado em que pese seu também grande número de jovens católicos não aderentes a grupos - tenha feito a balança pesar, neste caso, para o fator religião como critério de voto.

Num momento em que os grupos organizados e a hierarquia da Igreja Católica pregam uma maior intervenção na esfera pública justamente invocando valores religiosos, a que alguns autores chamaram de busca por uma "Neocristandade" (URQHART, 2002; CARRANZA, 2011), inclusive com a consigna "Católico vota em católico", alardeada pela Renovação Carismática no Brasil e América Latina (MARIANO, 2011, p. 249), soa estranho que uma maioria de respostas não sancione e até desconfie da dimensão religiosa/católica como critério moral de posicionamento público e político (ainda que, com um grau de adesão não desprezível entre $35 \%$ e $40 \%$ ). Talvez o peso considerável daqueles avulsos sem pertença a grupos organizados assim como dos grupos não identificados tenha contrabalançado o resultado de opinião desses jovens, supostamente previsível como conservadora e menos laica. Outra hipótese a essa contradição de uma opinião supostamente laica em meio religioso conservador definido (descontando-se o que pode ser contrabalançado pelos indefinidos e não agrupados, como afirmei) seria a de que o meio político é contaminador e que sempre é melhor se apartar das coisas do "mundo". Logo, mesmo religiosos e católicos que porventura se envolvam com o meio político também esses se maculam, não sendo considerados honestos nem de confiança. 


\section{Influência da religião na esfera pública (ciência, escola, justiça)}

D.1 - "Sempre que ciência e religião entram em conflito, a religião tem razão" (questão 132)

América Latina: Concordo $=22,2 \%$, concordo parcialmente $=42,7 \%$ (total $=64,9 \%$ ), indiferente $=5,7 \%$, discordo parcialmente $=22,2 \%$, discordo totalmente $=6,9 \%($ total $=29,1 \%), \mathrm{NR}=0,3 \%$

Europa: Concordo $=17 \%$, concordo parcialmente $=34,8 \% \quad($ total $=51,8 \%)$, indiferente $=13,3 \%$, discordo parcialmente $=28,1 \%$, discordo totalmente $=$ $5,2 \%($ total $=33,3 \%), \mathrm{NR}=1,5 \%$

O resultado dessas declarações aponta para a ideia de que o valor moral da religião prevalece sobre os conceitos científicos, 64,9\% para a América Latina e 51,8\% para a Europa católica. Esses índices percentuais coincidem com as recentes posições tomadas pela Igreja em relação às pesquisas em células-tronco e mesmo no caso do aborto, muitas vezes em tensão e desacordo com a comunidade científica e parcela da opinião pública. Enzo Pace (2012) afirma que na Europa, historicamente influenciada pelo catolicismo (Espanha, Itália, Irlanda, Bélgica Polônia, Portugal estendendose à França), a Igreja Católica tenta manter um protagonismo nas questões da "bioética" (compreendida como procriação assistida, eutanásia, pesquisa em células estaminais para investigar doenças neurológicas), intervindo diretamente na esfera pública. Para tal, ela invoca a doutrina da potesta indirecta (poder indireto), que lhe assegura o direito de intervir sobre a sociedade secular toda vez em que a "ordem natural" estiver ameaçada por pecado grave. Essa situação ela, a Igreja, julga acontecer, quando se atinge o paroxismo no "individualismo e relativismo ético" produtos da autonomia moderna, caindo-se, então, numa "manipulação da vida humana". Colocase assim como guardiã do "código da vida" (PACE, 2012, pp.30-44).

D.2 - "Os valores religiosos devem interferir nas decisões da justiça" (pergunta 144)

América Latina: Concordo $=23,2 \%$, concordo parcialmente $=38,6 \%$ (total $=61,8 \%$ ), indiferente $=7,0 \%$, discordo parcialmente $=20,6 \%$, discordo totalmente $=10,2 \%$ (total $=30,8 \%), \mathrm{NR}=0,4 \%$ 
Europa: Concordo $=10,4 \%$, concordo parcialmente $=28,9 \%$ (total $=59,8 \%$ ), indiferente $=22,2 \%$, discordo parcialmente $=26,7 \%$, discordo totalmente $=$ $11,9 \%$ (total $=38,6 \%$ ), NR $=0,7 \%$

Nessas declarações de princípios, com percentuais de 61\% na América Latina e 59\% na Europa católica, nesse segmento de jovens católicos, prevalece a mesma posição geral da Igreja, ou seja, o religioso é um valor moral para aplicação da justiça, mesmo no caso da justiça laica, processual e técnica. No caso da América Latina, em países de cultura pública impregnada secularmente de valores católicos, como o Brasil, o estudo de Ranquetat Júnior (2012, p. 62) apresenta no plenário da Suprema Corte a preeminência do crucifixo colocado acima dos demais símbolos cívicos para mostrar "justiça divina [como] superior à dos homens". Na opinião de altos magistrados, a imagem do crucificado funcionaria como um recurso "mnemônico" para lembrar ao "juiz que ele tem que ser justo (...) e não cometa o mesmo erro que ali foi cometido".

Para o caso das Europa católica, Enzo Pace (2012, p. 43) resume assim as pretensões morais da Igreja por sobre as instâncias jurídicas laicas: "a Igreja Católica se credencia como autoridade que custodia uma verdade pública: mestra indiscutível da ética, fundada sobre uma teologia que não pode ser posta em dúvida e que as leis do Estado devem obrigatoriamente refletir" .

\section{D.3 - "Todas as religiões devem ser ensinadas nas escolas públicas" (questão 136)}

América Latina: Concordo $=25,9 \%$, concordo parcialmente $=28,4 \%$ (total $=$ $54,3 \%$, indiferente $=5,7 \%$, discordo parcialmente $=23,8 \%$, discordo totalmente $=15,8 \%($ total $=39,6 \%), \mathrm{NR}=0,4 \%$

Europa: Concordo $=20,7 \%$, concordo parcialmente $=27,4 \%($ total $=48,1 \%)$, indiferente $=19,3 \%$, discordo parcialmente $=22,2 \%$, discordo totalmente $=$ $10,4 \%($ total $=32,6 \%)$

\section{D.4 - "Somente minha religião deve ser ensinada nas escolas públicas" (questão138)}

América Latina: Concordo $=9,1 \%$, concordo parcialmente $=15,7 \%$ (total $=24,8 \%$, indiferente $=6,4 \%$, discordo parcialmente $=40,3 \%$, discordo totalmente $=28,3 \%($ total $=69,9 \%), \mathrm{NR}=0,3 \%$ 
Europa: Concordo $=8,9 \%$, concordo parcialmente $=11,9 \%$ (total $=20,8 \%$, indiferente $=20 \%$, discordo parcialmente $=29,6 \%$, discordo totalmente $=28,9 \%$ (total $=58,5 \%), \mathrm{NR}=0,7 \%$

\section{D.5 - "Religião não deve ser ensinada em escola pública" (questão 140)}

América Latina: Concordo $=12,6 \%$, concordo parcialmente $=14,4 \%$ (total $=27 \%$ ), indiferente $=7,3 \%$, discordo parcialmente $=33,6 \%$, discordo totalmente $=31,7 \%$ (total $=65,3 \%), \mathrm{NR}=0,4 \%$

Europa: Concordo $=6,7 \%$, concordo parcialmente $=11,9$ (total $=18,6 \%$, indiferente $=12,6 \%$, discordo parcialmente $=30,4 \%$, discordo totalmente $=38,5 \%$ (total $=68,9 \%), \mathrm{NR}=0,7 \%$

De uma forma geral, as respostas convergem para a importância do fato religioso como um tema da formação educacional. Na América Latina, 65,3\% e na Europa, 68,9\% são favoráveis ao tema da religião figurar na grade escolar. Da mesma forma, em ambos os continentes, os jovens católicos surpreendentemente concordam com um ensino abrangente e inter-religioso, na América Latina, 54,3\%, e na Europa católica, 48,1\%, e rejeitam o ensino confessional, mesmo que este seja o do catolicismo, na América Latina, 69,9\% e na Europa católica, 58,5\%.

Em ambos os casos, me parece que o espírito de uma laicidade restritiva, que rejeita a presença da religião na esfera da formação escolar, não prospera. Por outro lado, mesmo na Europa católica, o que prevaleceu foi algo na direção da formulação de Debray para a França como o "Ensino do religioso", enquanto fato cultural, simbólico. Da mesma maneira, uma postura de colaboração igrejas-Estado no campo educacional já existe há anos, como na Alemanha, onde as religiões organizam nas escolas públicas, em caráter de matéria regular, a disciplina de estudo da religião (PORTIER, 2011, p.16).

O que chama atenção para a América Latina, onde iniciativas da hierarquia da Igreja Católica na proposição de um ensino religioso confessional foram à tônica no Brasil (GIUMBELLI, 2004) e na Argentina, onde o Estado financia a rede de ensino católica dando-lhe liberdade para traçar seu projeto educativo (ESQUIVEL, 2010, pp.158-59), encontrarmos com prevalência, mesmo em grupos declaradamente conservadores e proselitistas, uma maioria de declarações na direção de um ensino interreligioso e não confessional. 


\section{Conclusão}

Como método de análise das questões selecionadas em função da orientação temática e teórica que escolhi - o papel da religião no espaço público optei por fazer um cruzamento do conteúdo das opiniões (majoritárias e minoritárias) com a literatura especializada sobre o tema.

Primeiramente, examinei as frequências das respostas e as tendências que elas sugeriam, para, em seguida, consultar na literatura acadêmica voltada para a questão o que ela confirmava, refutava, problematizava nesses indicadores.

A resultante disso foi uma apreciação genérica por aproximação e especulativa da questão. Reconheço que, no momento da Jornada Mundial da Juventude do Rio em 2013, uma pesquisa qualitativa, munida de entrevistas, grupos focais poderia ter sido realizada para checar em pormenor as respostas oferecidas ao survey pelos participantes. No entanto, as análises resultantes desse texto, ainda que com esses limites, poderão ser mais uma contribuição, a partir de um universo juvenil e católico, para ser cotejada a outras similares e avançarem no conjunto o estado da arte da questão do papel da religião no espaço público dentro de uma perspectiva comparada em distintos espaços das sociedades modernas.

Do que pude apreender, grosso modo, para uma análise geral das opiniões dos jovens católicos da Jornada Mundial da Juventude, suas respostas indicam uma similitude entre os perfis da América Latina e os da "Europa mais católica"; ainda que, às vezes, com ênfases distintas. Sobre o papel público da religião, em ambos os segmentos, verifica-se uma atitude pendular: ora um desejo de influenciar a sociedade e o Estado, através dos valores cristãos, num modelo de Neocristandade; ora um afastamento do sagrado mais sublime de sua fé da contaminação do "mundo", segundo a fórmula cristã: "Dai a César o que é de César, dai a Deus o que é de Deus"! 


\section{Referências}

ASAD, Talal.

(2003). Formations of the secular. Stanford, Stanford University Press.

CASANOVA, José.

(1994). Public religions in a modern world. Chicago, University Chicago Press.

BAUBÉROT, (2015). Jean. Les laïcités dans le monde, Paris, PUF.

BLANCARTE, Roberto.

(2011). América Latina: entre pluriconfessionalidade y laicidad. Civitas, v.11, n. 2, p. 182-206.

BRUM PEREIRA, Asher Grochowalski.

(2014). Opus Dei na Jornada Mundial da Juventude: disputas acerca do que ser católico. Disponível em: http://www. anaisda29rba.org/\#!gt70/c1yrj. Acesso em 10 de outubro de 2014.

CAMURÇA, Marcelo.

(2015). Autonomia ou identificação orgânica entre a juventude católica e a instituição Igreja? Uma comparação entre estudos sobre as juventudes católicas no Brasil e na França. In: Péricles Andrade (Org.); Polifonia do Sagrado: pesquisas em Ciências da Religião no Brasil. São Cristovão, Editora da UFS. p. 15-29.

CARRANZA, Brenda.

(2011). Catolicismo Midiático. São Paulo, Idéias \& Letras.

CATROGA, Fernando.

(2006). Entre deuses e césares: secularização, laicidade e religião civil: uma perspectiva histórica. Coimbra, Almedina.

DUBET, François.

(2002). Le déclin de l'institution. Paris, Éditions du Seuil.

ESQUIVEL, Juan.

(2010). Notas sobre la laicidad em Argentina.

Debates do NER, ano 11, n.18, p.149-171.
FERNANDES, Rubem César.

(1993). Governo das Almas: as denominações evangélicas no Grande Rio. Rio de Janeiro, ISER. (mimeo).

\section{GIUMBELLI, Emerson.}

(2004). Religião, estado, modernidade: notas a propósito de fatos provisórios. Estudos Avançados, v. 18, n. 52, p. 47-52.

\section{GIUMBELLI, Emerson.}

(2013). Para estudar a laicidade, procure o religioso. In: Verónica Giménez Béliveau; Emerson Giumbelli (Orgs.). Religión, Cultura e política en las Sociedades del siglo XXI. Buenos Aires, Biblos. p. 43-68.

HERVIEU-LÉGER, Danièle.

(2003). Catholicisme, la fin d'un monde. Paris, Fayard.

(1996). Catolicismo: el desafio de memória. Sociedad y Religión, n.14/15, p.09-28.

LÖWY, Michael.

(2000). A guerra dos deuses: religião e política na América Latina. Petrópolis, Vozes.

LUBAC, Henri de.

(1986). Circundata Varietate. Comunicações do ISER, n०22, p.28-31.

MUIS, Jasper; IMMERZEEL, Tim.

(2017). Causes and consequences of the rise of populist radical right parties and movements in Europe. Current Sociology 65 (6), p. 22-39.

ORO, Ari Pedro.

(2011). A laicidade no Brasil e no Ocidente. Civitas, v.11, n. 2, p.221-237.

PACE, Enzo.

(2012). “A Igreja Católica na Itália como ator ético no espaço público europeu diante da bioética". In: 0R0, Ari et al. A Religião no Espaço Público: atores e objetos. São Paulo, Terceiro Nome. p.29-44.

ORO, Ari Pedro.

(2011). A laicidade no Brasil e no Ocidente. Civitas, v.11, n. 2, p.221-237. 
PORTIER, Philippe; LAGRÉE, Jacqueline.

(2010). La modernité contre la religion? Pour une nouvelle approche de la laïcité. Rennes, Presses Universitaires de Rennes.

PORTIER, Philippe

(2011). A regulação estatal da crença nos países da Europa Ocidental. Religião \& Sociedade, v. 31, n. 2. p. 11-28.

RANQUETAT JR., César Alberto.

(2010). 0 Acordo entre o governo brasileiro e a Santa Sé e a Lei Geral das Religiões: Estado, Religião e Política em debate. Debates do NER, no 18. p. 173-191.

RANQUETAT JR., César Alberto.

(2012). A presença da Bíblia e do crucifixo em espaços públicos no Brasil: religião, cultura e nação. In: Ari Oro; Carlos Alberto Steil; Roberto Cipriani; e Emerson Guimbelli (Orgs.); A Religião no Espaço Público: atores e objetos. São Paulo, Terceiro Nome. p. 61-79.

SOFIATI, Flávio Munhoz.

(2014). Renovação carismática e Teologia da Libertação: elementos para uma sociologia da juventude católica. In: Emerson José Sena Silveira; e Flávio Munhoz Sofiati (Orgs.); Novas Leituras do Campo Religioso Brasileiro. São Paulo, Idéias \& Letras. p.59-82.
WILLAIME, Jean-Paul.

(2011).Lesévolutionsen Europevers une laïcitéde reconnaissance et de dialogue. In: Symposium Internacional sur l'interculturalisme Dialogue Québec-Europe, Montreal. p.02-28..

URQUART, Gordon.

(2002). A armada do Papa: os segredos e o poder das novas seitas da Igreja Católica. São Paulo, Record.

VELASCO E CRUZ, Sebastião; KAYSEL, André; CODAS, Gustavo.

(2015). Direita volver! 0 retorno da direita e o ciclo político brasileiro. São Paulo, Editora Fundação Perseu Abramo.

\section{Recebido em}

abril de 2018

\section{Aprovado em}

setembro de 2018 